\title{
Minute Times Nanomole per Liter per Meter Squared
}

National Cancer Institute

\section{Source}

National Cancer Institute. Minute Times Nanomole per Liter per Meter Squared. NCI

Thesaurus. Code C111271.

Minutes times nanomoles per liter, divided by meters squared. 